\section{FLUID DYNAMICS}

\section{Many microbes make a superfluid}

Bacteria swimming in a fluid can reduce its viscosity to zero.

Unlike most liquids, superfluids have zero viscosity and so can behave in an unusual way, sometimes even defying gravity. Harold Auradou at the University of Paris-Sud in France and his colleagues found that they could alter the viscosity of a normal liquid solution by varying the concentration of Escherichia coli swimming in it. As the researchers spun the solution around in a rheometer (which measures viscosity), the motion of the bacteria's propulsive tails compensated for the forces between the molecules in the liquid, decreasing its viscosity. Once there were around 6 billion strong swimmers in suspension, the viscosity fell to zero.

Phys. Rev. Lett. 115, 028301 (2015)

\section{EVOLUTIONARY BIOLOGY}

\section{Ancient jellies had skeletons}

Fossils of comb-jelly ancestors show signs of rigid, skeletal spokes and plates, unlike their living, softbodied descendants.

All 150 known species of modern comb jellies, known as ctenophores, lack skeletons and use eight rows (or combs) of hair-like structures to swim. Qiang Ou of the China University of Geosciences in Beijing and his colleagues
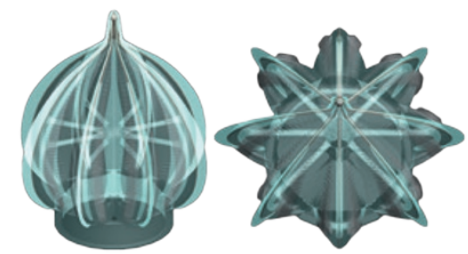

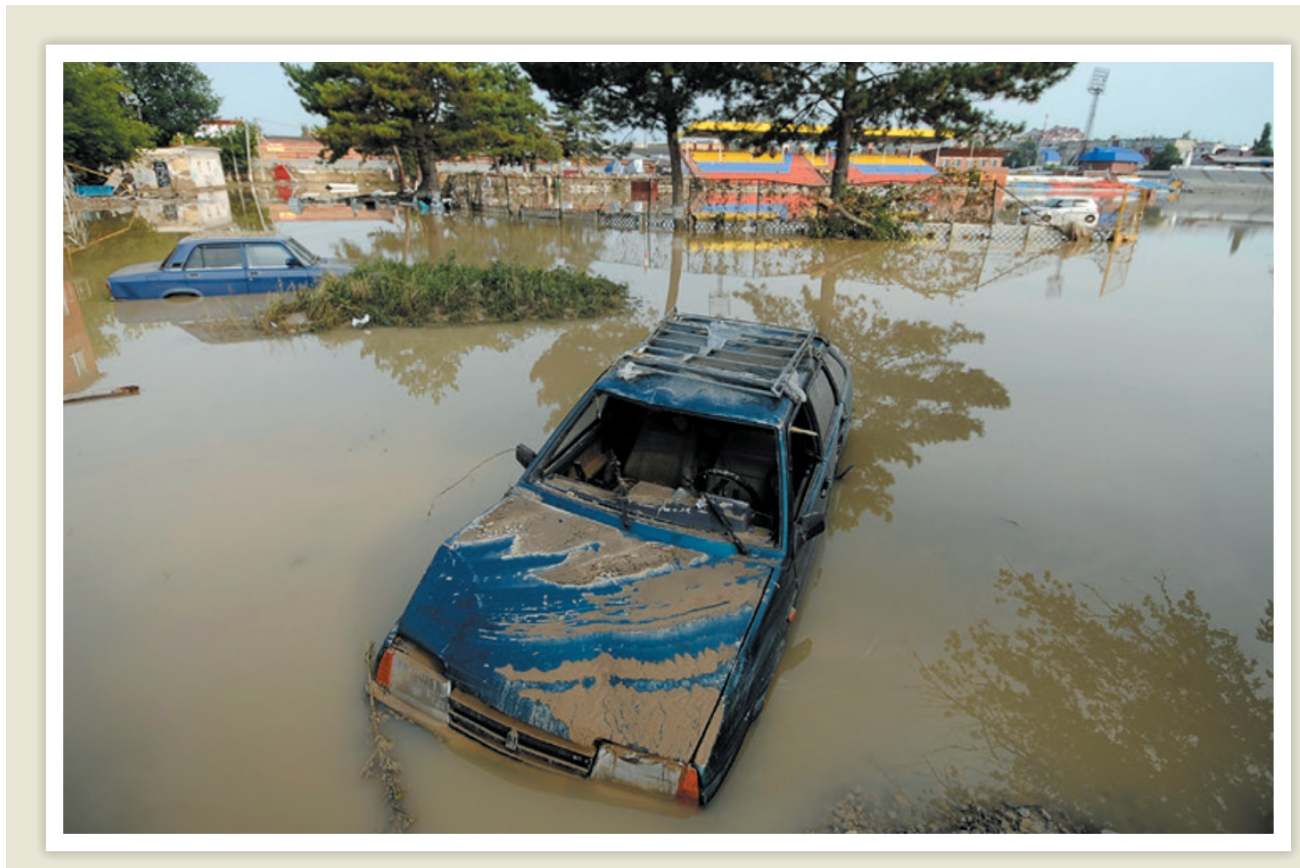

CLIMATE SCIENCE

\title{
Black Sea warming caused extreme rain
}

Intense rainfall that caused a devastating flash flood in a Russian town in 2012 (pictured) has been linked to the increasing surface temperature of the Black Sea.

The flood in the town of Krymsk killed more than 170 people after an unprecedented amount of rain - twice the previous record — fell in a single night. Edmund Meredith at the GEOMAR Helmholtz Centre for Ocean Research in Kiel, Germany, and his co-workers used an atmospheric model to study the sensitivity of this event to Black Sea warming. They found that simulations using current Black Sea surface temperatures produced a more than $300 \%$ increase in rainfall compared with models in which sea temperatures were similar to those of the early 1980 s.

The warmer waters destabilize the atmosphere, making it more likely that intense thunderstorms will form.

Nature Geosci. http://dx.doi.org/10.1038/ngeo2483 (2015) identified three new species of comb jelly from roughly 520-million-year-old Cambrian deposits in south China, and reanalysed these and other comb-jelly fossils. The fossils had combs and a similar basic body plan to living ctenophores, but also had radiating spokes and rigid plates (reconstructed models pictured), which probably provided support or served as armour.

The intense interactions of ancient comb jellies with their predators and prey may have led to this burst of diverse body types in the Cambrian period, the authors suggest.

Sci. Adv. 1, e1500092 (2015)

\section{Changing winds mean longer flights}

Shifting wind patterns caused by climate change could lengthen some airline flights, further raising carbon dioxide emissions.

Kristopher Karnauskas at
Woods Hole Oceanographic Institution in Massachusetts and his colleagues analysed the duration of 250,000 flights over the North Pacific and found that flight times varied with natural changes in wind speed at cruising altitude. Using climate models, the team predicts that climate change driven by greenhouse gases could cause part of the Pacific jet stream to shift into the corridor between Hawaii and the west coast of the continental United States, increasing average flight 